\title{
Antropologia como (In)Disciplina: notas sobre uma relação imprecisa entre campo e escrita
}

\author{
João Paulo Roberti Junior \\ Universidade Federal de Santa Catarina (UFSC), SC, Brasil \\ E-mail: joaoroberti@gmail.com \\ Diógenes Egidio Cariaga \\ Universidade Federal de Santa Catarina (UFSC), SC, Brasil \\ E-mail:didioaems@gmail.com

\section{Jean Segata} \\ Universidade Federal do Rio Grande do Norte (UFRN), RN, Brasil \\ E-mail: jeansegata@gmail.com
}




\section{Resumo}

O itinerário proposto no presente texto enseja traçar um panorama a partir da relação entre a pesquisa de campo e a escrita antropológica, refletindo sobre o lugar da descrição (etnográfica, cartográfica, modos de existência) na produção antropológica contemporânea. O objetivo não é pensar a história dos conceitos ou da própria disciplina, mas produzir considerações que apontem para os efeitos da pluralidade dos modos de pensar a relação entre as pessoas no mundo, associada aos modos de pensar a Antropologia. Reveste-se, assim, na tentativa de pensar ângulos e perspectivas em como um conjunto de referenciais teóricos e metodológicos pode dialogar com pesquisas alçadas em cenários e temas distintos. Sendo assim, é preocupação do presente texto refletir em uma interlocução interessada nos aspectos da relação e do lugar da etnografia na produção antropológica que problematize a postura de uma antropologia como (in) disciplina preocupada com a relação imprecisa entre campo e escrita.

Palavras-chave: Etnografia. Antropologia Simétrica. Escrita. Texto. Relação.

\section{Abstract}

The route that we propose in this text gives rise to draw a picture from the relationship between field research and anthropological writing, reflecting on the place of the description (ethnographic, cartographic, modes of existence) in contemporary anthropological production. It is our goal to think as history of the concepts or the discipline itself, but we are interested in yield considerations point to the effects of the plurality of ways of thinking about the relationship between people in the world associated with the ways of thinking anthropology. Lining up as well, trying to think of angles and perspectives on a set of theoretical and methodological frameworks can dialogue with standards in research scenarios and different themes. So is concern of this text, reflected in a dialogue interested in the aspects of the relationship and the ethnography of place in anthropological production that problematize the position of an anthropology as (un) discipline concerned about the inaccurate relationship between field and writing.

Keywords: Ethnography. Simmetryc Anthropology. Writing. Text. Relationship. 


\section{Introdução}

Se no final do século XX uma pessoa buscasse inventar um método de investigação por meio do qual se aprendesse a complexidade da vida social, talvez desejasse inventar algo parecido com a prática etnográfica da antropologia social. (Strathern, 2014a, p. 345)

$\mathrm{H}$ á muitas décadas a pesquisa de campo de caráter etnográfico tem sido o lugar privilegiado da produção de conhecimento no campo da Antropologia. Contudo, se ao tempo que para alguns é a própria etnografia que singulariza a Antropologia como campo de conhecimento acadêmico, isso não impede que os conceitos, métodos e técnicas da pesquisa etnográfica sejam alvo de críticas que produzem reflexões sobre o modo como são conduzidas as pesquisas. Nesse sentido, este texto é uma reflexão sobre modos de pensar ângulos e perspectivas sobre como o conjunto de referenciais teóricos e metodológicos dialogam com nossas pesquisas realizadas em cenários e temas distintos. Assim é preocupação do presente texto, uma interlocução interessada em refletir aspectos da relação e do lugar da etnografia na produção antropológica e vice-versa.

O itinerário proposto neste texto pretende traçar um panorama a partir da relação entre a pesquisa de campo e a escrita antropológica, para pensar o lugar da descrição (etnográfica, cartográfica, modos de existência) na produção antropológica contemporânea. O objetivo não é pensar a história dos conceitos ou da própria disciplina, mas interessa-nos produzir considerações que apontem para os efeitos da pluralidade de modos de pensar a relação entre as pessoas no mundo associada aos modos de pensar a Antropologia como possibilidade 
realizar conexões parciais e plurais da vida social (Strathern, 1991). O ponto de partida das reflexões que nos guiam está na relação entre a produção da pesquisa de campo, na interlocução com diferentes agentes e pontos de vista, a partir do processo de escrita da etnografia, em que esta operação é entendida como uma relação passível de simetrização e reversibilidade. Dessa maneira, acredita-se que o campo e a escrita não são polos opositivos na reflexão antropológica, segue-se uma aproximação ao modo como Lévi-Strauss (2006) conceitua quais sentidos estão em relação quando se toma, por exemplo, natureza e cultura como ferramentais conceituais capazes de operar reflexões sobre a produção do social a partir das diferenças, pondo em associação materiais heteróclitos reconectados pela comparação, capazes de apontar sentidos para o modo como diferentes agentes se pensam diante do e no mundo.

Neste artigo é possível reconhecer que o foco se dá a partir das leituras de autores que são localizados numa antropologia que se entende como "pós-social" (Viveiros de Castro; Goldman, 2012, Goldman, 2012)ํ. Nosso intuito não é realizar sínteses de releituras sobre perspectivas teóricas e metodológicas ao revistar os autores deste campo ou de decretar o fim de conceitos, mas pensar como produzir conceituações ou modos de conhecimentos a partir de relações e questões imbricadas na formação do antropólogo entre a pesquisa de campo e a escrita. Nesse sentido, não se trata de fixar a atenção entre as diferenças empíricas e conceituais desta relação na produção de conhecimento, mas sim pensar a partir delas, isto é, como delas emergem tons ou índices para refletir como em diferentes conjunções e modos de vida em que as pessoas atribuem sentido na produção da vida social.

Desde O Totemismo Hoje (1975), Lévi-Strauss demonstrou que certos conceitos podem ter sua validade questionada, entretanto, isto não significa que eles ainda não possam render discussões sobre a natureza de sua existência, considerando que suas posições são mais ambíguas do que definitivas. Como demonstrou o autor no conjunto de sua obra, tanto o totemismo, quanto a mitologia não está limitada a servir como índices estáticos a serem descritos funcionalmente, mas 
que o jogo entre tais termos pode demonstrar como certas operações estão eclipsando conceituações mais profundas sobre a produção do social.

Ao se referir à produção da vida social, alude-se a conjunto de posições anunciadas por Viveiros de Castro e Goldman (2012), em que os autores aproximam suas reflexões, produzidas a partir de suas pesquisas de campo e de suas etnografias, a um conjunto de autores interessados em pensar a antropologia como modo de associar pontos de vistas como um jogo que assume a simetria, a reflexividade e reversibilidade para compreender como em diferentes contextos, a agência do pensamento elabora relações sobre os modos de ser e de conhecer. Assim, a relação entre campo e escrita é problematizada não em termos da descrição do real/social ou outro termo monológico equivalente, mas que as palavras eleitas pelos autores - rede, multiplicidade e simetria - operam não somente como nexos que se aproximam da discussão mais conceitual, restrita ao campo da teoria antropológica, mas que tal posição reconhece que a produção de conceitos passa a assumir que as formulações produzidas entre e com quem nos comunicamos no campo e na escrita são relacionais e a partir delas é possível desestabilizar marcadores e posições que fixam dicotomias e divisores.

A preocupação de uma antropologia interessada em pensarse a partir de conceitos nativos (Viveiros de Castro, 2002) assume que a potência dos conceitos dos outros põe em suspensão a autoridade e a validade do pensamento dos modernos. Este movimento de desestabilização dos conceitos não se dá via negação, mas pela possibilidade de verificar como experiências mais concretas produzem efeitos ou deslocamentos sobre "os nossos modos" de produção de conhecimentos. Esse movimento pode ser apreendido nos termos propostos por Strathern e Toren (1996) no que diz respeito à inclusão de novos ângulos analíticos sobre questões elementares para o entendimento da vida social. O argumento das autoras em relação à obsolência do conceito de sociedade não reside na substituição de termos, mas em demonstrar que certas teorias se esgotam e que seus paradigmas chegaram o limite da exaustão, desta maneira, o conjunto de conceitos que ele produz deixa de produzir sentidos a modos de criação e produção do que se aponta como social. 
Contudo, o que se pensa em relação ao que está em jogo, ou que melhor, o que este jogo - entre campo e escrita - ainda pode render passa pela possibilidade de interrogar como distintas experiências sobre a vida social, constituem certa tensão entre a posição de duplo-vínculo do antropólogo em relação à atividade etnográfica e antropológica² . Nesse sentido, assume-se que leituras de análises que buscam “[... ] recuperar do estatuto de clichês temas cruciais do trabalho antropológico [... ]" (Stolze Lima, 2014, p. 9), são necessárias para que no esforço de dar relevo a pontos de vistas emergentes e/ou que estão por vir. Nesse sentido, a qualidade posição ambivalente de duplo-vínculo da atividade antropológica se dá pela via do reconhecimento que se esses vínculos são reconhecidos, é necessário assumir que a sua "invenção" se realiza no processo de produção antropológica que assume as conexões entre posições, agentes á ambientes múltiplos e heteróclitos.

\section{Descrevendo Redes: modos de existência e possibilidade limite da simetrização}

O que amplamente se convencionou como etnografia, albergou ao longo da própria história da Antropologia, inúmeros contornos semânticos que se moldaram e abrigaram descrições contingentes. Essas descrições são aqui entendidas, como sendo possíveis ao período histórico-metodológico que a Antropologia passa e passou, além dos inúmeros diálogos que possibilitaram uma aproximação e ao mesmo tempo um distanciamento dentro da disciplina.

Falar de etnografia até certo tempo fazia sentido para o nosso empreendimento, pois a virada hermenêutica (Geertz, 2013) possibilitou dar sentido explicativo ao mundo, interpretando uma alternativa contextual da ação entre os atores e compartilhando um campo de significado. Contornando uma compreensão proeminente, mas com agudas sensibilidades no esforço etnográfico da descrição, contribuindo muitas vezes, para o resultado de uma etnografia e não de um texto etnográfico.

Contudo, atualmente a etnografia na antropologia conta com a possibilidade de um alargamento. Este alargamento possibilita 
[...] repovoar [...] o que se pratica, especialmente a partir de recentes trabalhos nos quais se passa a dar mais consideração às múltiplas agências que formam aquilo que Bruno Latour costuma tratar por coletivos (Segata, 2014, p. 73)

Firmando-se a descrição como um saber que rejeita o mundo "moderno" e concebe-se a modernidade como um conjunto de práticas que em muitas medidas não coincidem com a teoria (Latour, 2008).

Para tal esforço, entende-se a etnografia como descrição. Isso faz pensar que "[...] nenhum pesquisador deve achar humilhante a tarefa de descrever - que, muito pelo contrário, é a realização máxima e mais rara [...] Se sua descrição precisa de uma explicação, não é uma boa descrição" (Latour, 2012, p. 213). Somente considerando esses aspectos é que se conseguirá escrever informes arriscados que não coloquem “[...] de lado nem a completa artificialidade do entendimento nem sua reinvindicação de exatidão e confiabiliade" (Latour, 2012, p. 195). É seguindo os atores mesmos e suas controvérsias ${ }^{3}$ que se pode compreender o social ${ }^{4}$. Portanto, algo que se chama aqui amplamente de "teoria pós-social" permite produzir efeitos que não se obteriam em nenhuma outra teoria do social. Portanto, registrar efeitos (que resultam, por exemplo, das controvérsias) possibilita ao mesmo tempo, uma imensa transformação e requer habilidade e destreza do pesquisador.

De maneira que, quando uma descrição necessita de explicação e ela não é demasiadamente boa, essa explicação poderia ser as entidades e o direcionamento do vínculo sujeito/objetivo que são utilizadas como "janelas" para observar e descrever. Assim, escrever relatos é considerar o ator-rede, de modo que a proporção de mediadores e intermediários será demasiadamente grande e de alguma forma arriscada (Latour, 2012). Uma vez consideradas as problemáticas da formação dos grupos sociais, das agências e da relação entre os entes, apontando a inclusão deles nas explicações acerca do social, se conduz a pensar a relação e a problematização do diálogo entre campo e escrita.

Um bom relato consiste em, conforme Latour (2012), tecer uma rede. Essa rede seria uma série de ações em que cada participante é tratado como um mediador completo. Pois até então 
[...] les sciences sociales n'ont pas simplement ignoré l'activité des médiateurs, elles ont brisé en deux le faire-faire, ressort de toute action à la voix «moyenne» qui permettait d'ignorer aussi bien la maîtrise que la détermination. (Latour, 2000, p. 9)

Contudo, a rede não seria a forma do texto ou mesmo o objeto exterior a ele. Ela é, segundo Latour, apenas um indicador da qualidade de um texto (Latour, 2012). Essa qualidade está na capacidade de trazer o mundo social à existência, no texto. Portanto, a rede designa uma expressão que busca avaliar “[...] quanta energia, movimento e especificidade nossos próprios relatos conseguem incluir" (Latour, 2012, p. 192). A rede é um conceito e não uma coisa, um modo 5 para se ver o social.

Assim, quando texto está pronto e acabado, a rede não é algo que está representado neste texto, mas sim aquilo que o prepara para substituir os atores em mediadores. A rede ${ }^{6}$ evoca dessa forma um campo de conhecimento das relações. Tão logo sejam tratados, não como intermediários, mas como mediadores, os atores tornam visível ao leitor o movimento do social. Igualmente, o relato em ANT deve ser uma narrativa e uma descrição ou uma proposição na qual todos os atores fazem alguma coisa e não ficam "somente observando" (Latour, 2012). O texto irá versar sobre quantos atores o escritor consegue registrar como mediadores e sobre até que ponto logra realizar o social.

Entretanto, a rede não seria a forma do texto ou mesmo o objeto exterior a ele. Até mesmo quando texto está pronto e acabado, a rede não é algo que está representado neste texto, mas sim aquilo que o prepara para substituir os atores em mediadores.

Ao assumir a possibilidade de que a etnografia é a imersão do começo ao fim, na escrita, inclui-se nesse sentido um processo de textualização como propõe Clifford (1998, p. 41) de que "[...] os dados constituídos em condições discursivas, dialógicas, são apropriadas apenas em formas textualizadas". Contudo, fazer e escrever não deveriam ser atividades separadas e diferentes, mas atividades relacionadas dialeticamente e interdependes (Emerson; Fretz; Shaw, 1995). “A etnografia [...] é uma prática peculiar de representar a realidade social de outros através da análise da experiência própria no 
mundo daqueles outros" (Emerson; Fretz; Shaw, 1995, p. 10). É preciso romper com uma textualização da cultura, seguindo o caminho de uma antropologia simétrica (Latour, 2002; 2008), possibilitando diluir a noção de que os "nativos" acreditam e nós, antropólogos, sabemos e conhecemos (Overing, 1985; Viveiros de Castro, 2002; Latour, 2008). Ingold $(2000 ; 2001)$ indica que o primado da construção em antropologia aliado á universalização do relativismo, conduziu á constituição de um vínculo artificial entre "Nós" e "Eles" porque separou o mundo passivo da realidade e os modelos cognitivos (visões de mundos) que o vivificam.

A possibilidade de romper com essa dicotomia, se translada na rede que é sempre resultado, ou seja, ela só se torna resultado na escrita. Se como propõe Derrida (1971; 1972), as "culturas" estudadas pelos antropólogos estão sempre se escrevendo, o resultado é sempre provisório. Pensando assim, como ação performática e não como resultado, e o que se ressalta são as capacidades de associações.

Dado isso, questiona-se quais os limites "assimetrizados" em uma simetria generalizada? Como colocar em aspecto a escrita de múltiplas agências, haja vista que nossa forma textual é traidora, ao insistir em sujeitos e objetos na composição de uma descrição? (Segata, 2014). O que nos preocupa é a produção de uma aceleração descritiva (Rifiotis, 2015 ) que sempre busque estancar categorias e localizar alguns rótulos em nossas descrições.

Poder-se-ía balizar, que não apenas a nossa descrição é traidora, mas que também as categorias com o qual se está operando são verticalmente traidoras. Ou seja, de alguma forma quando se está dividindo o "mundo" entre humanos e não humanos; ontologia orientada aos objetos; ontologia direcionada; ontologia achatada; palavras e coisas; linguagem e ser, entre outros conceitos, depende-se de uma história da Filosofia para lidar com esses conceitos, e também se está de alguma forma fazendo um movimento na contramão do empreendimento que se está trabalhando. Pratica-se, dessa forma, uma purificação na forma com que se buscava (ou ainda se busca ${ }^{7}$ ) na modernidade, pois política e natureza, sociedade e ciência não estão separados, tampouco aqueles que estas disciplinas se propõem estudar: são híbridos, são quase- 
sujeitos/quase-objetos dos quais não nos sentimos mais á vontade para dispor em um, ou outro polo (Rifiotis; Segata; Máximo; Cruz, 2011).

Contudo é preciso assumir uma imprecisão destes conceitos em uma antropologia que considere o métier descritivo como possibilidade de comparação entre modos de existência, pois é a descrição deste modo que possibilita a comparação. Existir é concebido como uma trajetória de superação de descontinuidades, agindo e sendo agido no curso das transformações. Deve-se, então,

Hablar de diferentes modos de existencia y pretender investigarlos com alguma precisión [...] El objetivo será obtener menos diversidade en el lenguaje pero más diversidad em los seres admitidos a la existencia. (Latour, 2013, p. 35)

Os modos de existência se correspondem como efeitos, desta forma existe aí imbricado um pluralismo ontológico que permite abordar sobre uma base mais equitativa e/ou reflexiva diante da comparação e criação de mundos em nossa descrição etnográfica (Latour, 2013). A questão aqui, é que a problemática já não é mais definida apenas pelas "associações" e pelo objetivo de seguir o curso da ação e (re) desenhar a "rede" mas sim aceitar o objetivo de redefinir também os nossos conceitos que estão pesadamente marcando as nossas descrições.

Contudo, tal como aponta Rifiotis (2014) afinal de contas, como se dá a escrita sobre a ação e a agência? Ou, de outra maneira, como podem ser solucionadas as exigências colocadas pela descrição de redes? Estamos amarrados em uma interobjetividade que nos instiga a pensar de que como compomos o mundo social. Além disso, é preciso assumir que, ação e a agência ${ }^{8}$, são campos teóricos, metodológicos e políticos em nossas descrições, pois o texto irá relacionar o campo de forças que está imbricado no ofício da descrição.

O problema de uma incomensurabilidade semântica que a etnografia assumiu, está contornada pela possibilidade de uma política etnográfica (Rifiotis, 2015). Pois, tratar campo e escrita como relação, é assumir uma postura dissidente em aceitar que muitas das escolhas que ela - a etnografia - transforma, envolvem decisões sobre o que escrever. O que muitas vezes submerge em uma disputa ontológica 
na produção destes agentes em relação aos coletivos no qual estamos empreendidos na realização da pesquisa.

\section{Pesquisa de Campo, Descrição Etnográfica e Atividade Antropológica: modos de produzir descrições (im)possíveis?}

Constantemente depara-se com debates sobre o que definiria o lugar da Antropologia no rol das ciências humanas e sociais. Definições do tipo o que é a Antropologia tendem a dividir e fragmentar as discussões com o objetivo de figurar paradigmas e modelos teóricos hegemônicos, resumindo as partes que compõem a produção do social em uma visão totalizadora da existência inquestionável do social por meio de seus avatares mais conhecidos: o social, o indivíduo e o grupo. Entre esses conceitos "o social" tem como seu correspondente adverso direto à natureza, que é também contraposto pelo conceito de cultura. Como demonstrou Lévi-Strauss (2006), esses conceitos mais do que opositivos são modos de compreender como operam certas transformações nas concepções e sentidos das categorias. Tais formulações nos oferecerem um conjunto de discussões sobre relações entre partes e todos nas dos conjuntos míticos, que nos auxilia a aproximar com o problema das partes e todo na atividade antropológica.

Nas formulações que antecedem $A$ origem dos modos à mesa (Lévi -Strauss, 2006), interessa a Lévi-Strauss demonstrar que as relações entre certos dualismos, como natureza e cultura, podem ser percebidas em operações que demonstram como, em certos conjuntos míticos, as narrativas exprimem cenários de máxima ou mínima conjunção (Lévi-Strauss, 2004), onde afere destaque o papel de certos mediadores, como o totemismo e o sacrifício, que buscam evitar a serialização ou a variação descontrolada. Lévi-Strauss (2006) introduz o tema da boa distância", que pode ser tomado como uma espécie de "manual de boa vizinhança" entre termos que apontam para conjunção ou disjunção. Se inicialmente a distinção entre mediadores se dava na oposição de dualismos, a operação proposta por Lévi-Strauss agora é compreender como entender a mediação entre mediadores. Essa operação busca compreender como um sistema se integra ao outro sistema, em que mediadores mais marcados são suspensos em favor da relação de 
mediação entre os mediadores, que possibilitaria compreender como eles estão ou são os próprios termos.

Da breve síntese das Mitológicas (volumes I e III) já exposta à imagem que se pretende extrair diz respeito aos modos como tratamos temas/conceitos que envolvem a antropologia: o trabalho de campo, a etnografia e a atividade antropológica como um conjunto composto de partes e todos, numa espécie de conjunção máxima ou disjunção máxima. Sabemos que as atividades conceituais enunciadas são composições que dão sustentação ao empreendimento antropológico, em certas situações nos são apresentadas como diferentes processos que constituem os modos de pensar na e da antropologia e em outras situações são tomadas de modos autônomos que constituiriam diferentes regimes de conhecimento.

Ingold $(2014 ; 2011)$ é um autor que tem insistido na diferenciação destes processos na antropologia, propondo alternativas ou dando novas perspectivas para "os temas cruciais de nosso trabalho". Contudo, antes de tecer algumas considerações sobre a crítica do autor, façamos um movimento sobre o modo como o pensamento dos modernos se constitui a partir da criação de divisores mobilizados em manter em separados certos regimes de conhecimento, conforme os postulados da antropologia simétrica de Latour (2012). A proposta de Latour (2012) nos permite desafiar e até mesmo superar as dicotomias do tipo saber tradicional versus saber científico ou natureza versus cultura, como pilares constituidores da Ciência Moderna, a proposta de uma pesquisa em rede que visa associar humanos e não-humanos, saberes e práticas alinhados a uma série de conexões que atravessam outros lugares e que precisam de novas conexões para continuar se estendendo (Latour, 2012).

O lugar da assimetria no pensamento dos modernos está em tomar o social como construído e o natural como o que é dado, nesse sentido, algumas formas de pensar a antropologia designam as informações levantadas na pesquisa de campo como dados ou reveladas por meio da etnografia, quanto a antropologia com um campo construído. Tal modo de pensar imprime a antropologia duas grandes divisões: uma interna que separa natureza e cultura e uma externa, que cria o nós e eles (Latour, 2012, p. 98-99). A proposição de superar 
esta dicotomia está na aposta dos híbridos como intermediários na possibilidade de tradução a partir da produção de redes simétricas como resultados ou a partir da própria ação dos sujeitos (Latour, 2012). Deste modo, pensamos ser possível estabelecer uma analogia entre os mediadores em ação de Lévi-Strauss (2006) e os híbridos em ação de Latour (2012) como meios de superar divisões rígidas na produção do conhecimento antropológico, o que nos inspira a pensar que não faz sentido querer manter limites fixos entre a pesquisa de campo, a etnografia e a antropologia.

A diferença entre estas categorias de análise da antropologia tendem a ser demonstradas como conceituais ou paradigmáticas vinculadas ao um contexto distintos na história da antropologia, como demonstrou Strathern (2013). O eixo da análise da autora é demonstrar que a crítica pós-moderna mesmo ao incluir em sua agenda a dialogia, multivocalidade, textualidade no questionamento da autoridade etnográfica e a escrita antropológica e a presença dos interlocutores como agentes textuais não produziram modos para superar a posição: nós - observadores x eles - observados, demonstrando que "[...] dessa forma, manipular os próprios conceitos para conceitualizar aqueles construídos como alheios estabeleciam distâncias entre escritor, leitor e subjeto de estudo" (Strathern, 2013, p. 57). Dessa forma, é preciso considerar que o destaque dado aos processos de enunciação, que compõem a relação entre a pesquisa de campo e a efetivação do texto etnográfico (monografia, dissertação ou tese), é produzido por meio de efeitos dos contextos de produção de conhecimento que conectam a produção de perspectivas teóricas empreendidas nos departamentos de pesquisa ao cotidiano de pessoas, animais, objetos, técnicas em pequenas cidades, aldeias, periferias, comunidades rurais, escolas, hospitais, shoppings e etc. Na avaliação da autora

[...] o poder de tais redes analíticas, contudo, é também o seu problema: teoricamente elas não têm limites [...]. Podemos também dizer que uma rede é tão comprida quanto puderem ser enumerados seus diferentes elementos. (Strathern, 2014b, p. 305) 
Nesse sentido, a percepção de Strathern (2014b) pensa a operação de redes e de relações como ações simultâneas, em que as questões envolvidas na produção de etnografias e o fazer antropológico põem em jogo diferentes contextos a serem negociados entre antropólogos, interlocutores e leitores ${ }^{10}$. Dessa maneira, o texto etnográfico é resultado de uma negociação que evoca diferentes pontos de vista sobre o contexto e o texto. Reconhecer a multiplicidade dos pontos de vistas engajados na atividade e escrita antropológica/etnográfica ou o inverso é o que a autora sugere como modos de pensar a produção de nexos de associação a partir de conexões parciais (Strathern, 1991), interessada em pensar multiplicidade de associações e conexões existentes nos modos como as pessoas elaboram refletem sobre a produção da vida social.

A ideia de multiplicidades de pontos de vista é contra o ideal pósmoderno que toma a etnografia como ponto de partida e de chegada em que viagem do etnógrafo, desestabilizaria a posição de sujeito e objeto, capaz de evocar imagens de alteridade. O que está em jogo no tipo de conexões que Strathern (1991) propõe passa por pensar a produção da vida social e de rede de relações sem que os diferentes sujeitos tenham uma matriz comum, que estejam em conexão permanente, mas que se tenha como horizonte que a produção de um texto etnográfico que sustente uma ficção persuasiva (2013), está nos modos como a produção da socialidade em diferentes cenários pode ser comparada a partir de escalas e conexões que emergem a partir deste movimento possível de ser apreendido por meio do momento etnográfico (2014a).

O momento etnográfico sobre o qual Strathern (1991) se refere tem haver com a própria história dos conceitos antropológicos e seus métodos, como a pesquisa de campo, assim como a complexidade em apreender textualmente a complexidade da vida social. Esse "enquadre" possibilita pensar campo e escrita são relações que contidas em si mesmo, pois o método etnográfico do antropólogo e suas estratégias asseguram a "invenção"11

Os etnógrafos se colocam a tarefa de não só compreender o efeito de certas práticas e artefatos na vida das pessoas, mas também recriar alguns desses efeitos no contexto de 
escrita deles. É claro que a análise (a "escrita") começa "em campo". (Strathern, 2014a, p. 350)

O argumento stratherniano aponta que esta divisão em dois campos - campo e escrita cria formas múltiplas de inter-relação, comumente a observação (campo) e a análise (escrita) são tratadas como formas a priori de produção de conhecimentos, contudo o momento etnográfico é uma relação (Strathern, 2014a) que envolve conjuntamente os dois campos. A perspectiva apontada por Strathern (2014a) a partir dos conceitos de imersão e momento etnográfico nos sugere a pensar quais os efeitos estas considerações produzem sobre temas cruciais do nosso

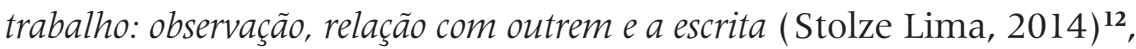
como desafiam-nos a produzir etnografias que sustentem que a vida social está em processo de construção a partir de certos relevos dados ao método etnográfico.

Para Strathern (2014a, p. 246-251) interessa estender certas categorias impressas em termos como observação participante, propondo o conceito de imersão, em que mesmo mantendo fortes imagens da observação participante, mas não se limita a uma condição dada ou secundária a observação e subjetiva aos objetivos da pesquisa. A condição de imersão é marcada pela ambivalência, pela intensidade das relações sociais e com as pessoas em campo e é parcial porque depende do modo como irá ser conectado ao processo de escrita e é por essa parcialidade que a escrita se faz presente em campo, e que, ao mesmo tempo o campo se caracteriza como um "[...] exercício antecipatório da escrita que virá" (Stolze Lima, 2014, p. 21). A escrita é a criação de um segundo campo, pois as informações de campo precisam ser rearranjadas, em um argumento textual endereçado a outros interlocutores: a escrita é recriar, produzindo uma descrição sobre os efeitos do campo.

O momento etnográfico é como se pontuou anteriormente, quando Strathern (2014a) demonstra que a escrita antropológica é condição de estar nos dois campos ao mesmo tempo, remete ao que Bateson (1998) aponta sobre os paradoxos na enunciação e da comunicação, de certo modo, podemos sugerir que campo e escrita podem ser tomados como enquadres entre modos de perceber o que está em jogo da condição de duplo-vínculo do antropólogo. O que assegura que essas 
conexões na possibilidade de reversibilidade dessas posições, pondo em comparação modos de existências múltiplos a partir de categorias, conceitos que se apresentem como nexos para associar diferenças

[...] a análise comparativa, afinal de contas, não gira em torno da aplicabilidade dos conceitos isolados, mas da comparação em sistemas inteiros. Isolar a ideia de "igualdade" neste caso. (Strathern, 2006, p. 221)

A suposta igualdade que asseguraria a comparação é justamente o que Strathern (2006) busca contrapor através de um conjunto de conceitos, como conexões parciais, jogar com o texto, na crítica o interpretativismo e da representação na antropologia ( Strathern, 2014a; 2013). A análise comparativa assegura uma posição reflexiva, em que antropólogo, interlocutor e leitor façam uso dos contextos a partir de suas intenções em produzir relações e conexões, desta maneira, o momento etnográfico só possível quando tomamos pretensão que os efeitos da imersão sejam associados em movimento, isto é habitar os dois campos ao mesmo tempo. Nesse sentido, a escrita antropológica tem o desafio de trazer a frente dos seus argumentos noções complexas que envolvem descrição mais movimento, como apontado por Viveiros de Castro (2006) sobre o xamanismo yanomami.

Ao se debruçar sobre as reflexões de Davi Kopenawa ditas a Bruce Albert sobre os modos yanomami de pensar o mundo a partir dos xapiripë - ancestrais animais ou espíritos xâmanicos ancestrais que interagem como os xamãs e o não xamãs yanomami, Viveiros de Castro (2006) nos oferece um desafio em pensar a descrição de conceitos tão elaborados em contextos de enunciados particulares sem que os submeta à tradução simplificadora ${ }^{13}$. Ao tocar numa questão dorsal para o entendimento dos modos de tradução via a comparação, tendo o xamanismo como nexo entre os pontos de vistas que compõem os modos de existência, o autor, Viveiros de Castro (2006), aponta que é preciso pensar nas diferenças entre o que está em jogo entre o conteúdo xâmanico e as formas xâmanicas de ação. Diferenciar aqui é não dividir, mas reconhecer que a narrativa de Kopenawa age ao mesmo tempo como modos de se e de conhecer. Assim, ao falar dos espíritos amazônicos as reflexões de Kopenawa e Albert não estão se 
dirigindo a uma noção metafísica de espírito, mas a considerações sobre características comuns sobre modos de existência, remetendo-se a uma noção de conceito que assuma multiplicidade virtual intensiva (Viveiros de Castro, 2006, p. 321).

Os termos da multiplicidade propostos por Viveiros de Castro (2010) aproximam-se do que Latour propõe como a alternativa via sua associologia tendo como modo de operá-la a Teoria Ator-Rede (Latour, 2012). Pois para Viveiros de Castro (2010), sustentando-se nas formulações de Deleuze e Guattari, a multiplicidade é um meta-conceito que assegura a possibilidade de produzir formas de pensar que tome como frente a não necessidade de julgamento e classificação para entender que os conceitos operam mais por uma singularidade intensiva do que por uma substancialidade do sujeito. Tal concepção de multiplicidade nos inspira a pensar que as relações entre o campo e a escrita podem ser lida nesta chave, em que, as diferenças desse conjunto passa por reconhecer que "[...] não há essência, as dimensões que a compõem não são constitutivas e nem critérios de inclusão classificatória (Viveiros de Castro, 2006, p. 102, tradução nossa).

Neste sentido é pouco produtivo pensar a trajetória da pesquisa como um movimento linear que se estabelece definições sobre um pretenso passo-a-passo, fixando o local da pesquisa de campo, o lugar das teorias, dos métodos e por fim, da escrita. Essa leitura termina por esvaziar a capacidade reflexiva da antropologia, isto é, criando domínios ontológicos distintos para a Antropologia e para Etnografia como aponta Ingold (2014). A etnografia como demonstra Ingold (2011) não se limita há uma qualitativismo adjetivador, talvez seja esta característica assumida por outros campos das ciências humanas que tenha provocado à diminuição do conceito por trás do método, isto é, a capacidade da Antropologia produzida a partir de Etnografias de colocar em suspensão por meio da comparação entre distintos modos de vida, como diferentes agentes em múltiplos contextos dão sentido a sua existência. Problematizar sobre isto talvez seja a postura de uma antropologia como (in)disciplina preocupada com o movimento das e nas relações, ou seja, antes uma aposta na potência das partes do que na crença sobre a existência do todo. 


\section{Notas}

1 O interesse de Viveiros de Castro e Goldman é demonstrar como é possível aproximar modos de pensar antropologia a partir autores que produziram suas reflexões iniciais a partir de cenários etnográficos diferentes: Bruno Latour a partir da produção da ciência e do conhecimento nos laboratórios franceses (2001), Marilyn Strathern a partir de sua etnografia somada a critica feminista nas terras altas da Melanésia (2006), assim Roy Wagner que com sua pesquisa sobre o sistema ritual Daribi (1972), empreendeu em A Invenção da Cultura (2010) reflexões sobre a ideia pensar a cultura a partir da cultura, assumindo que os nativos produzem sua própria antropologia.

2 Em Uma teoria sobre brincadeira e fantasia (1998), Bateson demonstra que o problema do duplo-vínculo exterioriza-se a partir do conflito instituído na comunicação entre interlocutores, em um regime de comunicação que envolve contradições e ambiguidades que, sem um enquadre, seja possível tomar contexto de enunciação, que possibilitaria aos interlocutores formular um conjunto de instruções que tornaria passível de compreensão as ambivalências na comunicação entre os participantes engajados no contexto da comunicação.

3 Segundo Venturini (2010), controvérsias são situações em que os atores não concordam (ou melhor, concordam com seu desacordo). Neste caso, relaciona-se com a ideia de algo que não está estabilizado como um conceito geral a fim de descrever uma incerteza compartilhada. Poderíamos considerar as controvérsias como estando também associadas ao hífen preso na denominação de ator (Teoria do Ator-Rede) que designa os fluxos de translação estabelecidos. Assim estamos buscando um ator-rede acrescentando-lhe os muitos traços deixados pelo fluído social ao qual reaparecem a partir de alguma modificação constatada. A escrita parte então como a objetificação do pensamento, o outro objetifica a experiência e faz lembrar algo que estava esquecido. Esta objetificação da escrita só é possível quando se mantém uma lista de cadernos que auxiliarão a compreender os movimentos descritos. Por conseguinte, a tarefa de escrever relatos de risco consiste em desdobrar os atores como redes de mediações - daí o hífen na palavra composta "ator-rede". Posicionamento não é "simples descrição", nem a mesma coisa que "desvelamento". "pelas costas" dos atores ou "forças sociais em ação" (Latour, 2012).

4 O social aqui entendido como algo não dado ou pronto. Mas como a possibilidade de admitirmos uma metafísica empírica no qual poderemos também compreender melhor o papel da agência na construção do social (LATOUR, 2012).

5 Assume-se aqui como um modo, pois se rejeita a noção de representação que tradicionalmente estaria ligada á ideia de espelhar o mundo.

6 Porém, questiona-se qual o limite da rede ou neste caso da descrição. Inferimos que quando a descrição é textualizada, ela é automaticamente finalizada. A composição do mundo acaba ali, mas seu valor final é momentâneo, corta-se a rede na escrita.

7 Mesmo com a ênfase em uma crise de representação na disciplina, tentamos de alguma forma preencher o abismo das divisões entre indivíduo e sociedade porque ainda não é fácil abandonar em nossas práticas os vínculos restritos a humanos e não humanos que no mundo moderno recebem a nomenclatura de objeto.

8 Segundo Rapport e Overing (2000), grande parte da literatura sobre agência, desde a época de Weber e Durkheim, tem procurado resolver diferenças e explorar os limites das capacidades individuais para agir independentemente dos constrangimentos estruturais. Contudo, o conceito de agência pode estar relacionado ao poder da descrição de organizar e compor um mundo. 
9 A análise proposta por Lolli (2012) é bastante esclarecedora sobre como a inserção deste tema é central na transformação, nos aspectos contínuos e descontínuos da variação mítica.

${ }^{10}$ É importante notar que o termo rede de relações é o mote das pesquisas coordenadas por Dominique Gallois publicadas na coletânea Rede de Relações nas Guianas (2005), onde os autores demonstram que o conceito de rede, referenciando em Latour (2012) foi empregado para pensar questões teóricas e metodológicas para criar um diálogo comparativo entre contextos etnográficos a fim de superar certas noções cristalizadas como identidade e território.

${ }^{11}$ No texto de Strathern, o termo invenção não corresponde ao sentido conceitual wagneriano, contudo, o uso das aspas pretende provocar certa ambiguidade a palavra no contexto do artigo, mais adiante será problematizada esta questão.

12 O lugar de outrem: não é a do outro, pois o outro seria correspondência direta, reconhecer o outrem é assumir certa distância entre si e os outros, mas reconhecer que se pode assumir as expressões dos outros. Reconhecer o outrem é pensar-se através não a partir da posição de/do outro, mas pelas relações que estão em jogo.

13 O texto de Viveiros de Castro se baseia no material produzido através dos diálogos entre o líder politico e xamã yanomami Davi Kopenawa e o antropólogo Bruce Albert (2004). O material produzido para o catalogo de uma exposição fotográfica pode ser compreendido com um preâmbulo para a publicação de The Falling Sky (2013).

\section{Referências}

BATESON, Gregoy. Uma teoria sobre brincadeira e fantasia. In: RIBEIRO, Branca T.; GARCEZ, Pedro M. (Org). Sociolinguística Interacional: antropologia, linguística e sociologia em análise do discurso. Porto Alegre: Editora AGE, 1998.

CLIFFORD, James. A experiência etnográfica: antropologia e literatura no século XX. Rio de Janeiro: UFRJ, 1998.

DERRIDA, Jacques. A escritura da diferença. São Paulo: Perspectiva, 1971.

La dissémination. Paris: Éditions du Seuil, 1972.

EMERSON, R.; FRETZ, R.; SHAW, L. Writing Ethnographic Fieldnotes. Chicago: The Chicago University Press, 1995.

GEERTZ, Clifford. A interpretação das culturas. Rio de Janeiro: LTC, 2013.

GOLDMAN, Márcio. Antropologia Pós-Social, perspectivas e dilemas contemporâneos: entrevista com Márcio Goldman. Revista Campos, [S.1.], n. 13, v. 1, 2012.

GALLOIS, Dominique T. Redes de relações nas Guianas. São Paulo: Humanitas/FAPESP/NHII, 2005. 
INGOLD, Tim. That's enough about ethnography! HAU: Journal of Ethnography Theory, [S.1.], v. 4, n. 1, 2014.

. Anthropology is not ethnography - Epilogue. In: Being

Alive. Essays on movement, knowledge and description. London and New York, Routledge, 2011.

. Culture, perception and cognition. In: . The perception of the environment: essays in livelihood, dwelling and skill. London: Routledge, 2000.

. From transmission of representations to the education of attention. In: WHITEHOUSE, Harvey. The debated mind: evolutionary psychology versus ethnography. Oxford: Berg, 2001.

KOPENAWA, Davi Y.; ALBERT, Bruce. The Falling Sky. Words of a Yanomami Shaman, Cambridge, Harvard University Press, 2013.

KOPENAWA, Davi Y. Xapiripë. In: ALBERT, Bruce; KOPENAWA, Davi Y. Yanomami, o espírito da floresta. Rio de Janeiro, Centro Cultural Banco do Brasil/Fondation Cartier, 2004.

LATOUR, Bruno. Factures/fractures: de la notion de réseau á celle d'attachement. In: MICOUD, André; PERONI, Michel. Ce Qui Nous Relie, [S.1.], Editions de l'Aube, La Tour d'Aigues, p. 189-208, 2000. LATOUR, Bruno. A esperança de Pandora. Bauru: EDUSC, 2001. . Jamais fomos modernos. Ensaio em Antropologia Simétrica. São Paulo, Editora 34, 2008.

. Reagregando o social: uma introdução à Teoria do Ator-Rede, Salvador/Bauru, EDUFBA/EDUSC, 2012.

. Investigación sobre los modos de existencia. Ciudad Autónoma de Buenos Aires: Paidós, 2013.

LÈVI-STRAUSS, Claude. A origem dos modos à mesa (Mitológicas III). São Paulo: Cosac \& Naify, 2006.

. O cru e o cozido (Mitológicas I). São Paulo: Cosac \& Naify, 2004.

. O Totemismo hoje. Petrópolis: Editora Vozes, 1975.

LOLLI, Pedro A. O contínuo e o discreto em Lévi-Strauss: transformações ameríndias. Tellus, Campo Grande, ano 12, v. 22, 2012.

OVERING, Joanna. Reason and Morality. Londres: Tavistock, 1985.

RAPPORT, Nigel; OVERING, Joanna. Agent and Agency. In: Social and Cultural Anthropology: key concepts. London: Routledge, 2000. p. $1-9$. 
RIFIOTIS, Theophilos. Etnografia no ciberespaço como repovoamento e explicação. Natal, RN. 29a Reunião Brasileira de Antropologia, 2014.

. Antropologia da ciência e Tecnologia: mapeando controvérsias contemporâneas, agência hibridismo e simetria. Florianópolis: UFSC, 25 mar. 2015. (Aula ministrada no Programa de Pós-Graduação em Antropologia Social).

STRATHERN, Marilyn. O efeito etnográfico. In: . O Efeito Etnográfico e outros ensaios. São Paulo: Cosac \& Naify, 2014a. . Cortando a rede. In: O Efeito Etnográfico e outros ensaios. São Paulo: Cosac \& Naify, 2014b.

. Fora de Contexto: ficções persuasivas da Antropologia. São Paulo, Editora Terceiro Nome, 2013.

. O gênero da dádiva. Problemas com as mulheres e problemas com a sociedade na Melanésia. Campinas: Editora UNICAMP, 2006. 1991.

Partial Connections. Update Edition. Oxford: Altamira Press,

SEGATA, Jean. A Etnografia como promessa e o "Efeito Latour" no campo da Cibercultura. Revista Ilha, Florianópolis, v. 16, n. 2, p. 69-87, 2014.

STOLZE LIMA, Tânia. Campo e escrita: relações incertas. R@U - Revista de Antropologia da UFSCar, São Carlos, v. 5, n. 2, 2014.

STRATHERN, Marilyn; TOREN, Christina. The concept of society is theoritically obsolet. In: INGOLD, Tim. Key debates in Anthropology. London: Routledge, 1996.

VENTURINI, Tommaso. Diving in Magma: How to Explore Controversies with Actor-Network Theory. Public Understanding of Science, [S.l.], v. 20, n. 4 maio de 2010.

VIVEIROS DE CASTRO, Eduardo; GOLDMAN, Márcio. Introduction to Post-Social Anthropology - Networks, multiplicies, and symmetrizations.

HAU: Journal of Ethnographic Theory, [S.1.], v. 2, n. 1, 2012.

VIVEIROS DE CASTRO, Eduardo. La Anti-Sociologia de las multiplicidades. In: VIVEIROS DE CASTRO, Eduardo. Metafisicas caníbales: líneas de antropologia postestructural. Buenos Aires: Katz Editora, 2010.

VIVEIROS DE CASTRO, Eduardo. O nativo relativo. Mana - Estudos em Antropologia Social, [S.1.], n. 8, p. 113-148, 2002a.

. A floresta de cristal: notas sobre a ontologia dos espíritos amazônicos. Cadernos de Campo, São Paulo, n. 14/15, 2006. 
. O nativo relativo. Mana - Estudos em Antropologia Social, [S.1], v. 8, n. 1, 2002b.

WAGNER, Roy. A invenção da cultura. São Paulo: Cosac \& Naify, 2010. . Habu: the innovation of meaning in daribi religion. Chicago and London: The University of Chigaco Press, 1972.

Recebido em 29/05/2015

Aceito em 19/11/2015 